\title{
Residual Stresses in DC cast Aluminum Billet: Neutron Diffraction Measurements and Thermomechanical Modeling
}

\author{
J.-M. Drezet ${ }^{\mathrm{a}}$, A. Evans ${ }^{\mathrm{b}}$ and T. Pirling ${ }^{\mathrm{c}}$ \\ ${ }^{a}$ LSMX, Ecole Polytechnique Fédérale de Lausanne \\ Station 12, CH-1015 Lausanne, Switzerland \\ ${ }^{b}$ Paul Scherrer Institut, PSI \\ $\mathrm{CH}-5232$ Villigen, Switzerland \\ ${ }^{c}$ Institut Laue Langevin, ILL \\ F-38042 Grenoble, France
}

\begin{abstract}
Thermally-induced residual stresses, generated during the industrial Direct Chill casting process of aluminum alloys, can cause both significant safety concerns as well as the formation of defects during down-stream processing. Although these thermally induced strains can be partially relieved by permanent deformation, cracks will be generated either during solidification (hot tears) or post-solidification cooling (cold cracks) when stresses exceed the deformation limit of the alloy. Furthermore, the thermally induced strains result in the presence of large internal stresses within the billet before further processing steps. Although numerical models have been previously developed to compute these residual stresses, most of the computations have been validated only against measured surface distortions. In the present work, the variation in residual elastic strains and stresses in the steady state regime of casting has been measured as a function of radial position using neutron diffraction in an AA6063 grain-refined cylindrical billet. These measurements have been carried out on the same billet section at Poldi at PSI-Villigen and at Salsa at ILL-Grenoble and compare favorably. The results are used to validate a thermo-mechanical finite element casting model and to assess the level of stored elastic energy within the billet.
\end{abstract}

Keywords: Aluminum alloys, residual stresses, neutron diffraction, finite element modeling, continuous casting PACS: 07.10.LW

\section{INTRODUCTION}

The fabrication of aluminum alloy extrusion products typically involves a number of steps starting from the semi-continuous casting of the cylindrical billet using a process known as direct chill (DC) casting and, depending on the alloy composition, ending with a post-extrusion heat treatment. Of the different processing stages, the casting process is particularly challenging since it gives rise to large thermally induced strains that can result in several types of casting defects including distortions, cracks, porosity, etc. Although these thermally induced strains can be partially relieved by permanent deformation, cracks will be generated either during solidification (hot tears) or postsolidification cooling (cold cracks) when stresses exceed the deformation limit of the alloy [1]. Furthermore, the thermally induced strains generally result in the development of large internal stresses within the billet after cooling to room temperature. These residual stresses will cause significant downstream processing and safety issues during the sawing stage prior to extrusion, when the billet is cut into section of about $1 \mathrm{~m}$ in length [2]. For large diameters (typically higher than $350 \mathrm{~mm}$ ) and high-strength alloys (2xxx and 7xxx series), the residual stresses can lead to saw pinching first and then to crack initiation. In both cases, the elastic energy released upon sawing may cause personnel injury and equipment damage. Currently, the most common technique for quantifying residual stresses that arise during manufacturing is through the use of numerical process models, generally using finite element (FE) mathematical techniques [3]. To be effective and accurate, these models require a significant understanding of the processing route and knowledge of the material's mechanical and physical behavior over a range of temperatures. The computation of stress evolution including billet distortions and residual stresses during the DC casting of 
aluminum alloys has been the scope of many studies since the late 1990's [3-9] and nowadays is a well-established technique. However, validation of these models, often done by comparing the computed and measured distortions at the billet surface, e.g. the butt-curl [7] and the rolling face pull-in for rolling sheet ingots [8], remains challenging. Experimental validation against the computed room-temperature residual stresses is limited simply owing to the difficulty of measuring the internal strains in large castings and the high variability in the measurements. While some measurement techniques are available for quenching [10] or welding [11], they remain rare, uncertain, and are usually limited to only one or two components of the stress tensor near the surface of the casting $[12,13]$. In the past, destructive methods (hole-drilling [14], cut compliance [15]. etc.) have been used for measuring residual elastic strains. Physical methods such as X-ray, ultra-sound, or neutron diffraction (ND) have now become very attractive, since they can provide all of the components of the elastic strain tensor. With the development of powerful neutron beams, it is now possible to measure the residual elastic strains rather deep in light metal alloy systems such as aluminum and magnesium alloys since these metals are relatively transparent to neutrons. Such measurement allow for sophisticated model validation. In the current publication, residual strain measurements have been undertaken at POLDI [16] the Swiss neutron diffractomer located at PSI-Villigen and at SALSA [17], the neutron strain imager located at ILL-Grenoble, on the same AA6063 round billet section $160 \mathrm{~mm}$ in radius (R), $0.6 \mathrm{~m}$ in length and cast at $66 \mathrm{~mm} / \mathrm{min}$. The goal of the present paper is to present these measurements and to validate a thermomechanical finite element (FE) model of the DC casting process applied to cylindrical extrusion billets. This model is built in Abaqus and fully detailed in section II, in particular, the minimum billet section-length necessary to maintain the distribution and magnitude of as-cast residual stresses is determined numerically. It is shown that this section-length has to be higher than three times the billet radius, $48 \mathrm{~cm}$ in the present study. It is also demonstrated that the stress tensor is diagonal in the $(r, \theta, z)$ cylindrical reference frame, thus reducing to three the number of unknown stress components. Section III provides a description of the principles of residual strain measurements using neutron diffraction. The residual stress measurements, along with a comparison of these results to the values predicted by the FE model, are provided in Section IV.

\section{THERMO-MECHANICAL FE MODEL OF THE STRESS BUILD-UP DURING CASTING AND THE STRESS RELAXATION DURING SAWING}

\subsection{Mechanical Behavior}

The AA6063 aluminium alloy (composition $0.52 \mathrm{Si}$ wt. pet., $0.60 \mathrm{Mg}$ wt. pct. and 0.18 wt. pct. $\mathrm{Fe}$ ) has a solidification interval of $557^{\circ} \mathrm{C}-655^{\circ} \mathrm{C}$ [18]. The alloy is modelled as an elastic material with low Young's modulus $(0.5 \mathrm{GPa})$ above its coherency temperature of $610^{\circ} \mathrm{C}$ corresponding to a solid fraction of $65 \%$ for a grain refined structure, to simulate liquid behaviour. Below the coherency temperature, one has to address the effects of strain and strain rate on stress formation and hence the alloy is treated as an elasto-viscoplastic material exhibiting strain hardening. The constitutive equation governing this behaviour is given by a modified Ludwik's equation [19]:

$$
\bar{\sigma}=\mathrm{K}(\mathrm{T})\left(\gamma_{\mathrm{p}}+\gamma_{\mathrm{p}}^{0}\right)^{\mathrm{n}(\mathrm{T})}\left(\frac{\dot{\varepsilon}_{\mathrm{p}}}{\dot{\varepsilon}_{\mathrm{p}}^{0}}\right)^{\mathrm{m}(\mathrm{T})} \text { with } \gamma_{\mathrm{p}}=\int_{\mathrm{T}<\mathrm{T}_{0}} \dot{\varepsilon}_{\mathrm{p}} \mathrm{dt}
$$

where $\bar{\sigma}$ is the von Mises equivalent stress, $\dot{\varepsilon}_{p}$ is the equivalent inelastic strain rate. The internal variable $\gamma_{p}$ is equal to the accumulated inelastic strain from a reference temperature $T_{0}$ down to the current temperature. Therefore, the effect of the plastic strain on the stress is neglected above $T_{0}$, which corresponds roughly to an annealing temperature above which dynamic recovery of the structure is very efficient. $T_{0}=423^{\circ} \mathrm{C}$ for the alloy under study. The constant $\gamma_{p}^{0}$ is taken equal to 0.001 and $\dot{\varepsilon}_{p}^{0}$ is a reference strain rate taken equal to $1 s^{-1}$. Ludwik's equation is very well suited to describe the transition from time independent plasticity at low temperatures to time dependent plasticity (visco-plasticity) at high temperatures [19] since the rheological parameters $K(T), m(T)$ and $n(T)$ are continuous functions of the temperature $T$. The first parameter is the consistency of the alloy and has units of a stress $(\mathrm{MPa})$. The second and third parameters are the strain rate sensitivity, and strain hardening exponent. In the current work, the values of $\mathrm{K}, \mathrm{m}$, and $\mathrm{n}$ but also of the thermal expansion coefficient were taken from experiments conducted during two different European research programs [20-21]. At temperatures lower than $300^{\circ} \mathrm{C}$, the behaviour of the alloy is insensitive to the applied strain rate $(\mathrm{m}=0$ in Eq. 1), but presents significant strain hardening. At higher temperatures, the strain hardening is negligible ( $\mathrm{n}=0$ in Eq. 1), but the stress response becomes rate dependent (viscoplastic behaviour). At intermediate temperatures $\left(250-300^{\circ} \mathrm{C}\right)$, both strain hardening 
and rate effects are present. Equation (1) allows taking into account these phenomena. Other thermo-physical properties, such as thermal conductivity and specific heat, and the solidification path of the alloy were calculated using the software ProPHASE ${ }^{\circledR}$, based on a model proposed by Sigli et al. [22].

\subsection{Computation of Stress Build-up during DC Casting}

The DC casting process is simulated using a coupled thermo-mechanical model implemented in the FE code ABAQUS ${ }^{\circledR}$ 6.7, and based on the work of Drezet et al. [3]. The finite element mesh consists of $11 \mathrm{~mm}$ high layers of axisymmetric linear elements. The coordinate system is fixed with respect to the ingot, and the incoming flow of liquid metal is modelled through the activation of successive layers at a rate which corresponds to the experimental casting speed of $66 \mathrm{~mm} / \mathrm{min}$ and pouring temperature of $670^{\circ} \mathrm{C}$. The lateral cooling conditions are translated along the external faces of the slab according to the casting speed. The thermal boundary conditions account for primary cooling through the mould, air gap formation and secondary cooling when the water hits the ingot and flows along its surface [23]. The DC casting of a $160 \mathrm{~mm}$ radius billet is simulated with a total cast length of $1100 \mathrm{~mm}$. This length ensures that steady state conditions are reached within the simulation. Figure 1 shows the temperature field during casting; the liquid pool appears in white together with the radial, axial and hoop stress components after the billet has cooled down to room temperature. The numerical model results indicate that the shear component $\sigma_{\mathrm{rz}}$ is negligible as compared to the three other stress components. Therefore the stress tensor is diagonal in the (r, $\theta, \mathrm{z})$ cylindrical system. The stresses are tensile in the interior of the billet and become compressive at its surface. This is explained by the stress build up during casting: the cold shell, which is efficiently cooled by the water striking the billet surface, hinders the contraction of the core region, which is still hot. This effect is known as the "skin-core" effect reported by Drezet and Rappaz [24] and also observed during the quenching of heat treatable alloys [25]. The high tensile stresses (about $100 \mathrm{MPa}$ ) in the core region are thought to be one of the origins of crack formation of cracks during casting [6].
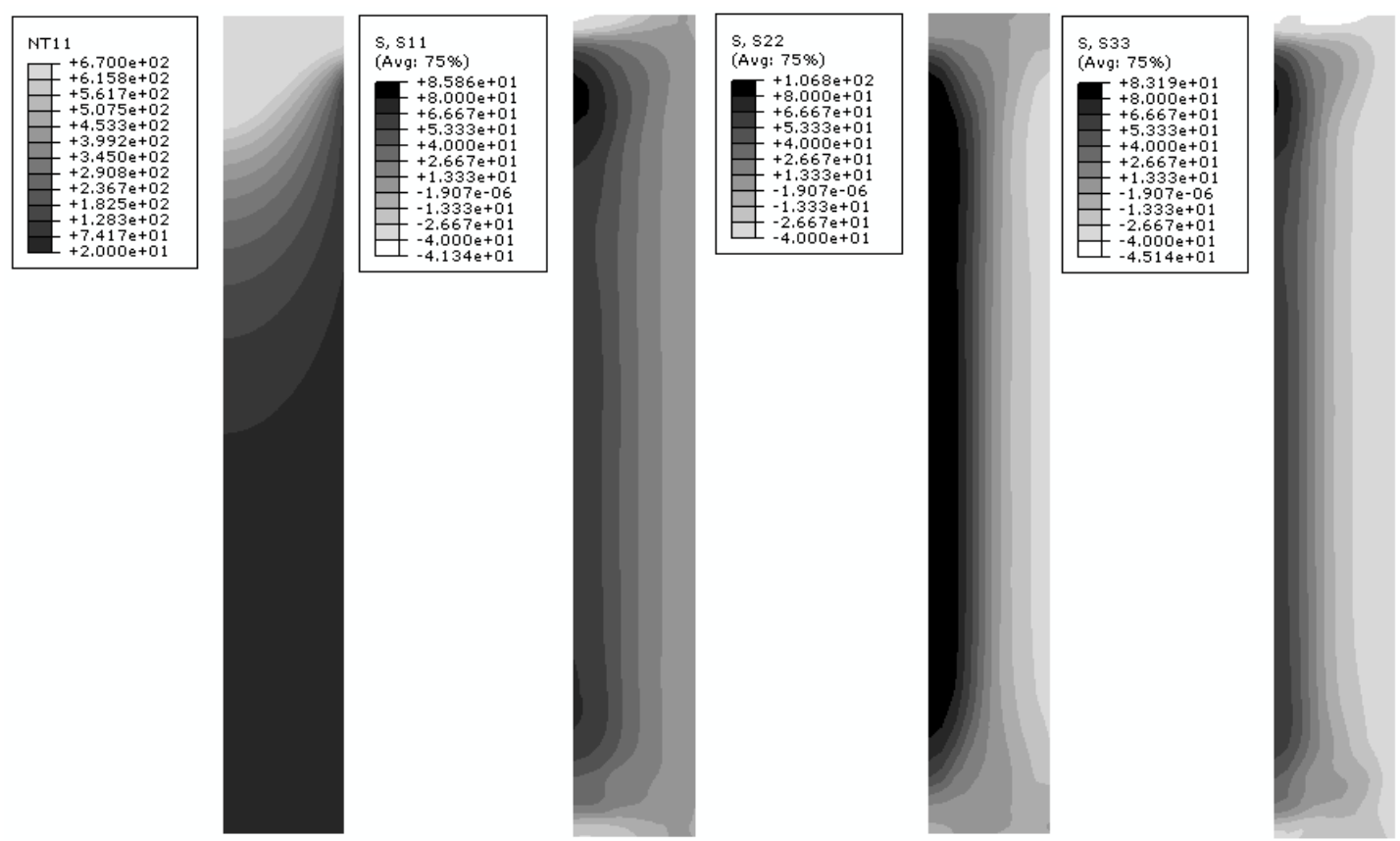

FIGURE 1: Temperature field in ${ }^{\circ} \mathrm{C}$ during casting (left) and radial, axial and hoop stress components in MPa after the ingot has cooled down.

The sawing itself is modelled by the removal of elements, similarly to the strategy adopted by Drezet et al. [26] to study the possible crack initiation and propagation. Prior to this, the axisymmetric results from the casting simulation, above, are exported onto a 3D domain since the sawing process itself is not axisymmetric. Nevertheless, only half of the billet has to be modelled owing to the presence of a centre-line symmetry plane. It is shown that the movement of the saw from right the left induces a stress relaxation over a distance of $1.5 \mathrm{R}$ on both sides of the groove. The result is that, for residual stress measurements, the minimum billet section-length must be greater than 
at least three times the billet radius to ensure that the residual stresses at its mid-height are not relaxed during sawing. In the current context, this corresponds to a section-length of $48 \mathrm{~cm}$.

\section{NEUTRON DIFFRACTION MEASUREMENTS}

\subsection{Neutron Diffraction}

POLDI and SALSA are neutron diffraction instruments designed for strain measurements through the accurate determination of lattice spacing. In a stressed material, the lattice spacing acts as a kind of strain gauge. If $\mathrm{d} 0$ and $\mathrm{d}$ are, respectively, the stress-free and actual lattice spacing for a given plane family, then the elastic strain is given by $\varepsilon=(\mathrm{d}-\mathrm{d} 0) / \mathrm{d} 0$. Using Hooke's law, the measured strain can be converted to stress. The position of the diffraction peak intensity gives a measure of the average strain, whereas its width is related to strain fluctuations and to possible plastic deformation. Peak intensities can also provide information about texture. Diffraction can be understood in terms of the Bragg's law $\lambda=2 \mathrm{~d} \sin \theta$ where $\mathrm{d}$ is the lattice spacing, $\lambda$ the wavelength and $2 \theta$ the diffraction angle. Therefore in order to measure the lattice spacing for determining strains and stresses, either the wavelength is fixed and the diffraction angle is measured (monochromatic angular dispersive) or the diffraction angle is fixed and the wavelength determined (polychromatic time-of-flight). In the case of monochromatic where only one diffraction peak is recorded, for fcc metals such as aluminum, the (311) diffracting planes are commonly used to measure the strain since they do not accumulate significant intergranular stresses and hence exhibit similar behaviour as that of the bulk. The (311) is also recommended for use in the measurement of residual strains by neutrons in aluminium alloys by the ISO VAMAS standard (G.A. Webster: VAMAS TWA 20 standard, ISO Technical report, 2001). This is the case of the measurements made on SALSA. In contrast with the time of flight method, many diffraction peaks are measured corresponding to several families of lattice planes. Using a full pattern refinement, an average lattice parameter is determined from which strain and stress is subsequently calculated. With this method the range of elastic and plastic anisotropies are averaged, giving strain response akin to that of the bulk. This is the case with the POLDI measurements.

POLDI is a so-called time-of-flight instrument which means that the detector is placed at a fixed diffraction angle $\left(90^{\circ}\right)$ and that in contrast to monochromatic instruments a broad wave length spectrum is used. For the measurements at POLDI [16], a $3.8 \mathrm{~mm}$ collimator was used to define the sampling gauge volume. This rather large sample gauge volume $\left(3.8 \times 3.8 \times 8 \mathrm{~mm}^{3}\right)$ gave reasonable measurement times, typically 2 hours per position per strain component. A series of stress free reference samples, for measurement of the reference lattice constant $\mathrm{d}_{0}$, were also acquired. These samples were electro-discharge machined along the billet radius every $20 \mathrm{~mm}$ in order to account for any variation in $\mathrm{d}_{0}$ with position within the billet that may be present due to long range chemical inhomogeneities, i.e. macrosegregation. Located at ILL-Grenoble, SALSA [17] uses a large crystal monochromator to select a particular neutron wavelength. The material to be studied is placed in this monochromatic neutron beam, and the scattered neutrons are collected on a large 2D detector to determine accurately the lattice spacing. The wavelength is constant $(1.66 \AA)$ ) and the position of the diffraction peak is recorded on a position sensitive detector. For the measurements at SALSA, $2 \mathrm{~mm}$ radial focusing collimators were used to reduce experimental errors introduced by the optics. A rather large instrumental gauge volume $\left(2 \times 2 \times 15 \mathrm{~mm}^{3}\right)$, but with good lateral resolution in the scan direction, gave reasonable measurement times of on average $30 \mathrm{~min}$. Again, a series of stress free reference samples, for measurement of the reference lattice constant $\mathrm{d}_{0}$, were acquired.

\subsection{Residual Strains and Stresses}

In the DC casting process of billets, the elastic stress/strain tensor has only four components due to the axisymmetric billet geometry and casting conditions. Furthermore, as the billet section used for the residual strain measurements was taken from the central part or steady-state regime of casting, the stress tensor depends only on radial position. FE calculations have shown that the shear stress component of $\sigma_{\mathrm{rz}}$ is negligible thus further reducing the stress and strain tensors to three components, radial, hoop and axial. These tensors are therefore diagonal in the $(\mathrm{r}, \theta, \mathrm{z})$ reference frame and can be described by Hooke's law, where E is Young's modulus (71.3 GPa) and $v$ the Poisson's ratio (0.3):

$$
\left(\begin{array}{l}
\sigma_{r} \\
\sigma_{\theta} \\
\sigma_{z}
\end{array}\right)=\frac{E}{(1+v)(1-2 v)}\left(\begin{array}{ccc}
1-v & v & v \\
v & 1-v & v \\
v & v & 1-v
\end{array}\right)\left(\begin{array}{l}
\varepsilon_{r} \\
\varepsilon_{\theta} \\
\varepsilon_{z}
\end{array}\right)
$$




\section{MEASURED VERSUS COMPUTED STRESSES AND STORED ELASTIC ENERGY}

Residuals strains on a 0.6 m long AA6063 billet section, taken from the steady-state region of the casting, were measured at the two neutron diffractometers, POLDI and SALSA. The typical grain size in this casting was $100+/-$ 30 microns. As measuring time was reduced at Salsa owing to a higher neutron flux, roughly thirty two residual strain measurements were made along the radius of the billet in $\sim 5 \mathrm{~mm}$ increments. Furthermore, since the AA6063 alloy was grain refined, no texture was present in the sample.

The radial distribution of the three stress components has been calculated at each radial position using Eq. 2. These stresses are shown in figures 2 and 3, along with the predicted stresses from the FE model. The error of the stress measurement is reported on each of the points using the elastic constants. The statistical error is larger for the axial stress at the billet centre owing to a longer beam path length, but still below $10 \mathrm{MPa}$. The centre of the billet is in tri-axial tension whereas its surface is in compression in the hoop and axial directions: these results are in full agreement with previous works [4-5] and are explained by the so-called skin-core effect [24]. Furthermore, the agreement between the stress components measured at SALSA and POLDI and the FE predictions is very good for all three components. The FE results always fall within the measured values except near the billet surface for the hoop stress and at the billet centre for the axial stress. The locations where the axial and hoop stress components change sign are also very close to the measured ones. Note also that the measured radial stress component at the billet surface is $-1.65 \mathrm{MPa}$ at POLDI and $4 \mathrm{MPa}$ at SALSA whereas it should be zero. This gives us an idea of the precision that can be obtained with such neutron measurements.
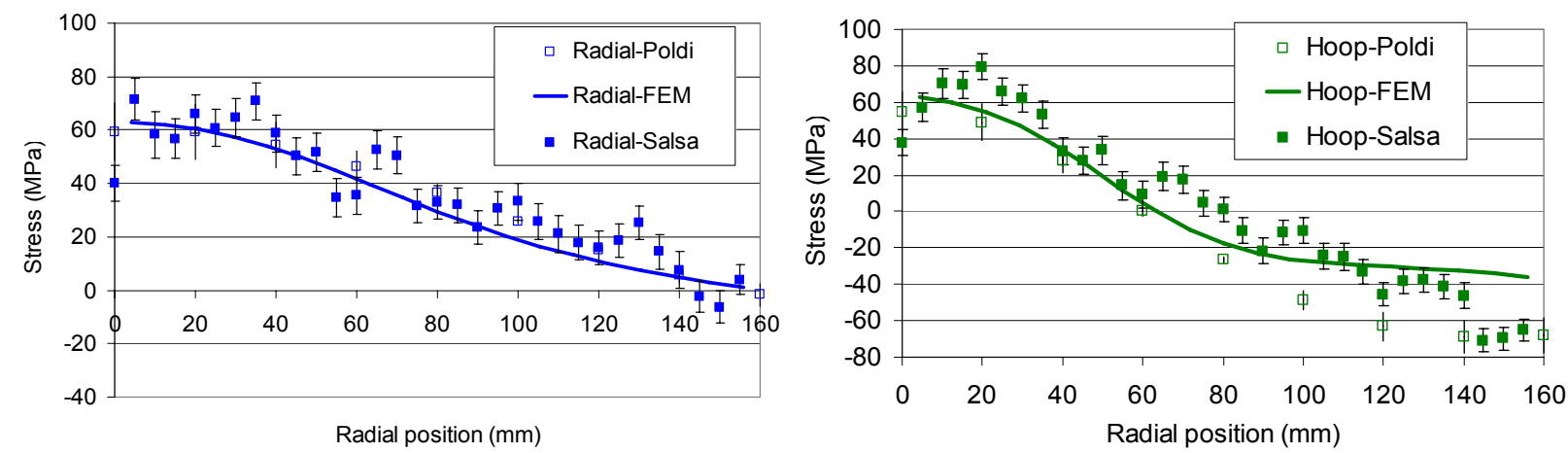

FIGURE 2: comparison between computed (FEM) and measured stresses: radial (left) and hoop (right) components.

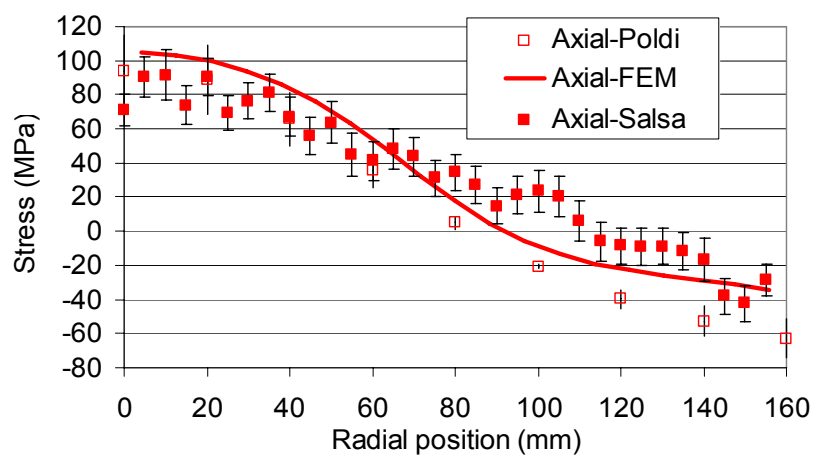

FIGURE 3: comparison between computed (FEM) and axial stress component measured at Poldi and Salsa.

The stored elastic energy in a billet section of length $\mathrm{H}$ and radius $\mathrm{R}$ is given by:

$$
\mathrm{W}=\int_{\mathrm{V}}(\sigma: \varepsilon) \mathrm{dV}=2 \pi \mathrm{H} \int_{0}^{\mathrm{R}}\left(\sigma_{\mathrm{r}} \varepsilon_{\mathrm{r}}+\sigma_{\theta} \varepsilon_{\theta}+\sigma_{\mathrm{z}} \varepsilon_{\mathrm{z}}\right) \cdot \mathrm{rdr}
$$

As the FE results fall within the measured values (cf. figures 2-3), the stored energy can be calculated using the FE predictions. Calculating integral (3) yields $\mathrm{W} / \mathrm{H}=2.4 \mathrm{~kJ} / \mathrm{m}$ for our billet sample $(\mathrm{R}=160 \mathrm{~cm})$. This leads to a volumetric stored elastic energy of $29.6 \mathrm{~kJ} / \mathrm{m}^{3}$. The higher this value, the higher is the risk to get erratic dissipation of energy when sawing the billet [26]. In particular, this value increases with increasing casting speed thus limiting productivity. Casting recipes should be adapted in order to decrease this value. In addition, this stored energy is 
comparable to that found after quenching of 6xxx aluminum thick plates [25]. This can be explained by the fact that thermally induced deformations and associated stress build up are comparable in casting and in quenching.

\section{CONCLUSION}

Prior to performing the residual stress measurements, the FE model of extrusion billet casting was first used to determine the minimum section-length which can be sawed from the billet without significantly relaxing the residual stresses at its mid-height. Based on the computation results, a billet section whose length exceeds three times the billet radius retains residual stresses which are similar in magnitude to the as-cast steady-state predicted value. Then, the as-cast residual stresses have been measured on a $0.6 \mathrm{~m}$ long steady-state section of an AA6063 DC cast extrusion billet using the neutron diffractometers POLDI and SALSA. The corresponding residual stresses indicate that while the billet centre is in high tri-axial tension, the billet skin is in bi-axial compression owing to the skin-core effect. This stress distribution is similar to the stress state encountered in quenching and welding. The measurements coming from POLDI and SALSA agree remarkably well. They have been used to validate the FE model of DC casting. Considering the numerous input parameters entering into the model (alloy properties, cooling conditions, etc.), the comparison between the measured and computed results is excellent and allows calculating the stored elastic energy that might dissipate erratically during sawing of the billet thus posing serious safety concerns.

\section{ACKNOWLEDGEMENTS}

The authors express their acknowledgements to Alcan ATI Valais for providing the billet section on which neutron diffraction measurements have been carried out, the Institute Laue-Langevin in Grenoble (France) and the Swiss Neutron Source at PSI-Villigen (Switzerland) for the provision of beam time.

\section{REFERENCES}

1. W. Boender, A. Burghardht, E. P. van Klaveren, J, Rabenberg, Light Metals 2004, A. T. Tabereaux Ed., TMS, 2004, pp. 679-684.

2. Ludwig, J.-M. Drezet, B. Commet, B. Heinrich, Modelling of Internal Stresses in DC casting and Sawing of High Strength Aluminum Alloys slabs, in Modeling of Casting Welding and Advanced Solidification Processes, Eds. C.-A. Gandin and M. Bellet, pp. 185-192, Nice, 2006.

3. J.-M. Drezet, M. Rappaz, Met. Mat. Trans. A, 27A, 1996, pp. 3214-3225.

4. B. Hannart, F. Cialti, R. V. Schalkwijk, Light Metals 1994, A. T. Tabereaux Ed., TMS, 1994, pp. 879-887.

5. H. Fjaer and A. Mo, Met. Mat. Trans. A, 21B, 1990, pp. 1049-1061.

6. J. Sengupta, S.L. Cockcroft, D.M. Maijer, A. Larouche, Mat. Sc. Eng A, 397, 2005, pp. 157-177.

7. W. Droste, J.-M Drezet, G.-U Gruen and W. Schneider in Continuous Casting, Eds: K. Ehrke and W. Schneider, DGM, Wiley-VCH, Frankfurt 2000, pp. 175-183.

8. W. Droste, G.-U Grün, W. Schneider and J.-M. Drezet in Light Metals, Eds. Wolfgang Schneider, TMS 2002, Seattle, pp. 703-708.

9. K. Escobar et al.: On the residual stress control in aluminium alloys 7050, Materials Science Forum vols. 396-402 (2002), p. 1235-1240.

10. D. Bru, J. Devaux, J.M. Bergheau and D. Pont in Mathematical Modeling of Weld Phenomena 3, H. Cerjak, ed., The Institute of Metals, Graz, AUS, 1997, pp. 456-63.

11. S. Ganguly, M. E. Fitzpatrick and L. Edwards: Comparative neutron and synchrotron X-rax diffraction studies to determine residuals stress on an as-welded AA2024 plate, Materials Science Forum vols. 790-491 (2005), pp. 223-228.

12. J. Moriceau in Light Metals (TMS), 1975, p. 119-133

13. S. A. Levy et al.: Residual stress measurements for studying ingot cracking, Light Metals (TMS), 1974, p. 571-585.

14. J. Lu, Handbook of Measurement of residual stresses, Society for Experimental Mechanics, Inc. The Fairmont Press, Ed. J. Lu, 1996.

15. H. Hao, D.M. Maijer, M.A. Wells, S.L. Cockcroft and R.B. Rogge: Prediction and measurement of residual stresses/strains in a direct chill casting magnesium alloy billet in Magnesium Technology, (2005), 223-228.

16. Poldi, Pulse overlap time-of-flight diffractomer, POLDI, Paul Scherrer Institut, Villigen, Switzerland, http://poldi.web.psi.ch/

17. Salsa, Strain imager for engineering applications SALSA, Institut Laue Langevin, Grenoble, France http://www.ill.eu/instrumentssupport/instruments-groups/instruments/salsa/

18. J.-M. Drezet and A. Phillion: As-cast residual stresses in an aluminum alloy AA6063 billet: neutron diffraction measurements and finite element modelling, in Met. and Mat. Trans. Vol. 41 A, pp. 3396-3404, December 2010.

19. B. Magnin, L. Maenner, L. Katgerman, S. Engler, Ductility and rheology of an Al-4.5\%Cu alloy from room temperature to coherency temperature, Mat. Sc. Forum, 217-222, 1996, pp.1209-1214

20. European Modelling Programme on Aluminium Casting Technology EMPACT, EU research project, 1997-2000.

21. The virtual cast house - development of a process chain model of aluminium direct chill casting of tailored productsVirtual Casting, VIRCAST, EU research project, 2001-2004.

22. C. Sigli, L. Maenner, C. Sztur and R. Shahani, Phase diagram, solidification and heat treatment of aluminium alloys, Proc. International Conference on Aluminum Alloys, T. Sato, S. Kumai, T. Kobayashi and Y. Murakami Eds, JILM, 1998, pp.87-98.

23. J.-M. Drezet, M. Rappaz, G.-U. Gruen and M. Gremaud in Vol. 31A, June 2000, pp. 1627-1634.

24. J.-M. Drezet and M. Rappaz, Ingot Distortions and Residual Stresses in Direct Chill Casting of Aluminium Alloys in Proceedings of the 4th European Conference on Residual Stresses, ECRS 1996, SF2M, Eds. S. Denis et al., Cluny, France, pp. 357-366.

25. F. Heymès, B. Commet, B. Dubost, P. Lassince, P. Lequen and G.M. Reynaud in $1^{\text {st }}$ International Non-ferrous Processing and Technology Conference, St Louis, Missouri, 10-12 march 1997.

26. J.-M. Drezet, O. Ludwig, C. Jaquerod and E. Waz in Inter. Journal of Cast Metals, 2007, vol. 20, no. 3, p. 163-170. 